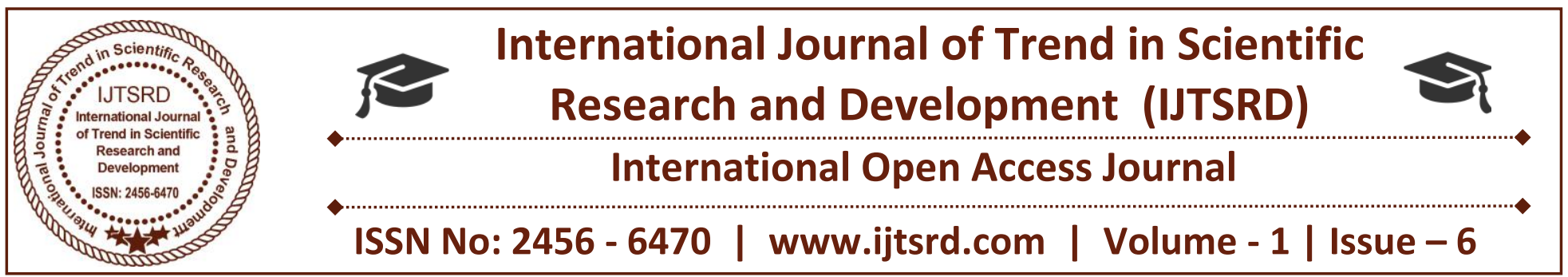

\title{
Effect of Contributing Parameters over Material Removal Rate in Machining Incoloy 825 using Electric Discharge Machining (EDM)
}

\author{
Vigneshwaran N.K. \\ UG Student, Department of Mechanical \\ Engineering, K. Ramakrishnan College of \\ Technology, Trichy, Tamilnadu, India \\ Vignesh Kumar S \\ UG Student, Department of Mechanical \\ Engineering, K. Ramakrishnan College of \\ Technology, Trichy, Tamilnadu, India
}

\author{
Vishnu Prabhu S \\ UG Student, Department of Mechanical \\ Engineering, K. Ramakrishnan College of \\ Technology, Trichy, Tamilnadu, India \\ Ricordey Arumaidoss F \\ UG Student, Department of Mechanical \\ Engineering, K. Ramakrishnan College of \\ Technology, Trichy, Tamilnadu, India
}

\begin{abstract}
Manufacturers of modern era aim on improved quality at low cost. The production rate is one of the major contributors to the cost of the product which depends upon machining time. The work concentrates on obtaining the influential parameters for material removal rate and machining time based on input parameters such as current, Pulse on time and Pulse off time. It was encountered that feed was the most important contributed for material removal rate. The $\mathrm{R}$ - squared value for Material Removal Rate is $96.55 \%$ and adjusted $\mathrm{R}$ - squared is $94.48 \%$.
\end{abstract}

Keywords: Quality, Production Rate, Material Removal Rate and Machining Time

\section{INTRODUCTION}

Murray J.W et al [1] study the debris produced while machining the work piece with electrical discharge machining process and reviewed that the size of the debris varied from 1 nanometer to 10 micrometer. Bai Shao et al [2] develop a model to predict the crater formation is micro EDM. Mohammed Antar et al [3] identified the suitable regimes for EDM process and optimize the operating parameters. Guo Linng [4] developed magnet suspension spindle system for micro EDM process. Annamalai et al [5] studied the effect of input parameters over material removal rate and surface roughness using surface methodology. Radhakrishnan et al [6] investigated the impact of contributing parameter over the removal rate and surface roughness in machining alloy of aluminum with response methodology. Dinesh et al [7] analyzed and optimized the machining parameters in $\mathrm{CNC}$ turning using response surface methodology and taguchi analyze. Manish and Pradhan et al [8] reviewed the methods of modeling and optimization of electrical discharge machining process. Dinesh $\mathrm{S}$ et al [9] used Response surface Methodology for predicting effect on Material Removal Rate and Surface roughness while turning duplex stainless steel. Dinesh et al [10] used Grey relational analysis for analyzing the effect of machining parameter in grinding of Magnesium alloy. Godwin Antony et al [11] used Grey relational analysis for analyzing the effect of performance parameter in Computerized IC Engine Using Diesel Blended with Linseed Oil and Leishmaan's Solution.

\section{Experimental Set up}

In the present experimental study, speed, feed and depth of cut have been considered as process 


\begin{tabular}{|c|c|c|c|c|c|}
\hline \multicolumn{2}{|c|}{$\begin{array}{c}\text { Machining } \\
\text { Parameter }\end{array}$} & & $\begin{array}{c}\text { Level } \\
\mathbf{1}\end{array}$ & $\begin{array}{c}\text { Level } \\
\mathbf{2}\end{array}$ & $\begin{array}{c}\text { Level } \\
\mathbf{3}\end{array}$ \\
\hline $\begin{array}{c}\text { Discharge } \\
\text { Current }\end{array}$ & $\mathrm{I}_{\mathrm{p}}$ & $\mathrm{A}$ & 6 & 14 & 20 \\
\hline $\begin{array}{c}\text { Pulse Off } \\
\text { Time }\end{array}$ & $\mathrm{T}_{\text {off }}$ & $\mu \mathrm{s}$ & 9 & 6 & 3 \\
\hline $\begin{array}{c}\text { Pulse On } \\
\text { Time }\end{array}$ & $\mathrm{T}_{\text {on }}$ & $\mu \mathrm{s}$ & 40 & 60 & 85 \\
\hline
\end{tabular}

Table 1 Working Range of Parameters

variables. The working range of each parameter with their units is listed in table 1 . Table 2 shows the experimental results. The Experiments was conducted using Sparkonix Series (S35) electrical discharge machining and the surface roughness was measured using TR200 surface Roughness tester.

\begin{tabular}{|c|c|c|c|}
\hline Si.No & $\begin{array}{l}\left.\text { Current( } I_{p}\right) \\
\text { Ampere }\end{array}$ & $\begin{array}{l}\text { Pulse ON } \\
\text { Time } \\
\text { (Ton) } \\
\text { seconds }\end{array}$ & $\begin{array}{l}\text { Pulse OFF } \\
\text { Time } \\
\text { (Toff) } \\
\text { seconds }\end{array}$ \\
\hline 1 & 6 & 40 & 9 \\
\hline 2 & 6 & 60 & 9 \\
\hline 3 & 6 & 85 & 9 \\
\hline 4 & 14 & 40 & 6 \\
\hline 5 & 14 & 60 & 6 \\
\hline 6 & 14 & 85 & 6 \\
\hline 7 & 20 & 40 & 3 \\
\hline 8 & 20 & 60 & 3 \\
\hline 9 & 20 & 85 & 3 \\
\hline
\end{tabular}

Table 2 Experimental results

\section{RESULT DISCUSSION}

\section{Response surface Methodology}

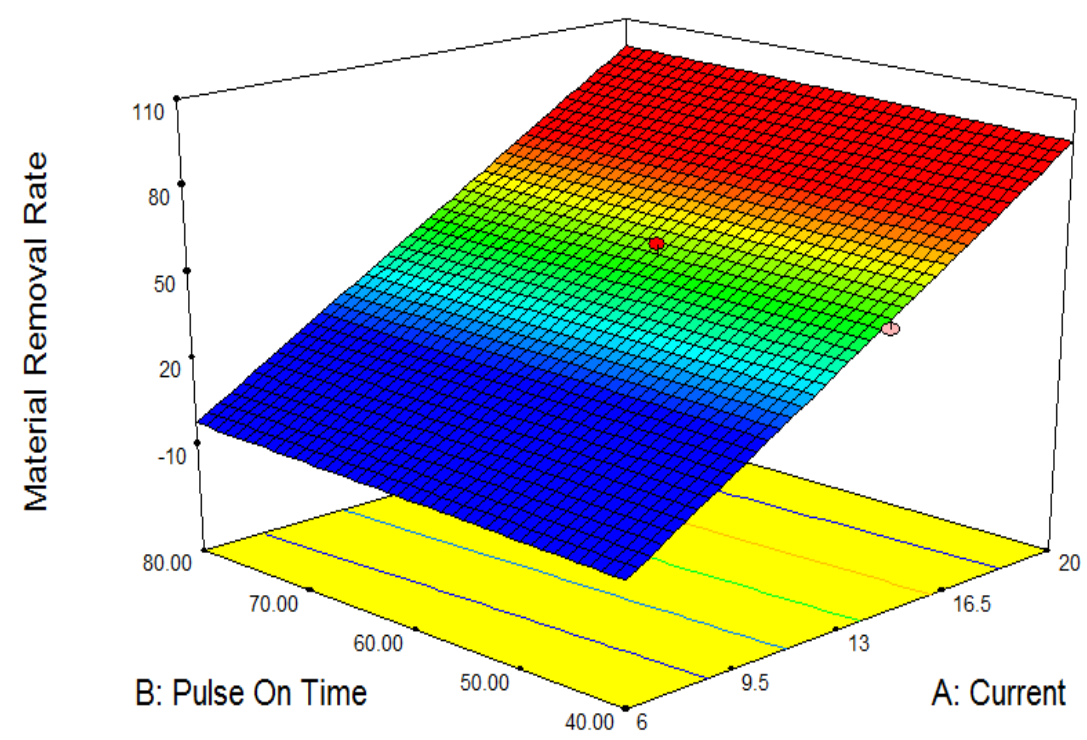

Figure 1 Effect of pulse on time and current over material removal rate.

Figure 1 shows the effect of pulse on time and current over material removal rate. The Material removal rate remains constant throughout the range of pulse on time whereas the material removal rate has increased linearly with increase in current. The maximum Material removal rate was attained at 20 amperecurrent and 80 seconds of pulse on time. 


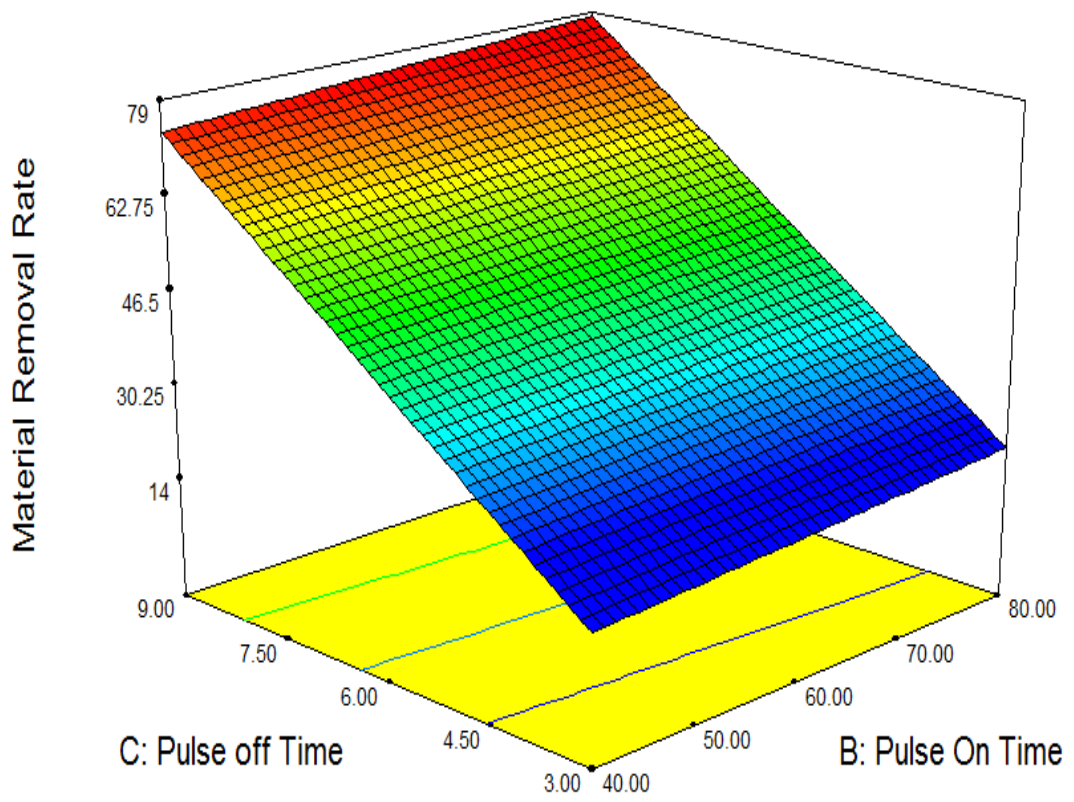

Figure 2 Effect of pulse on time and pulse off time over material removal rate.

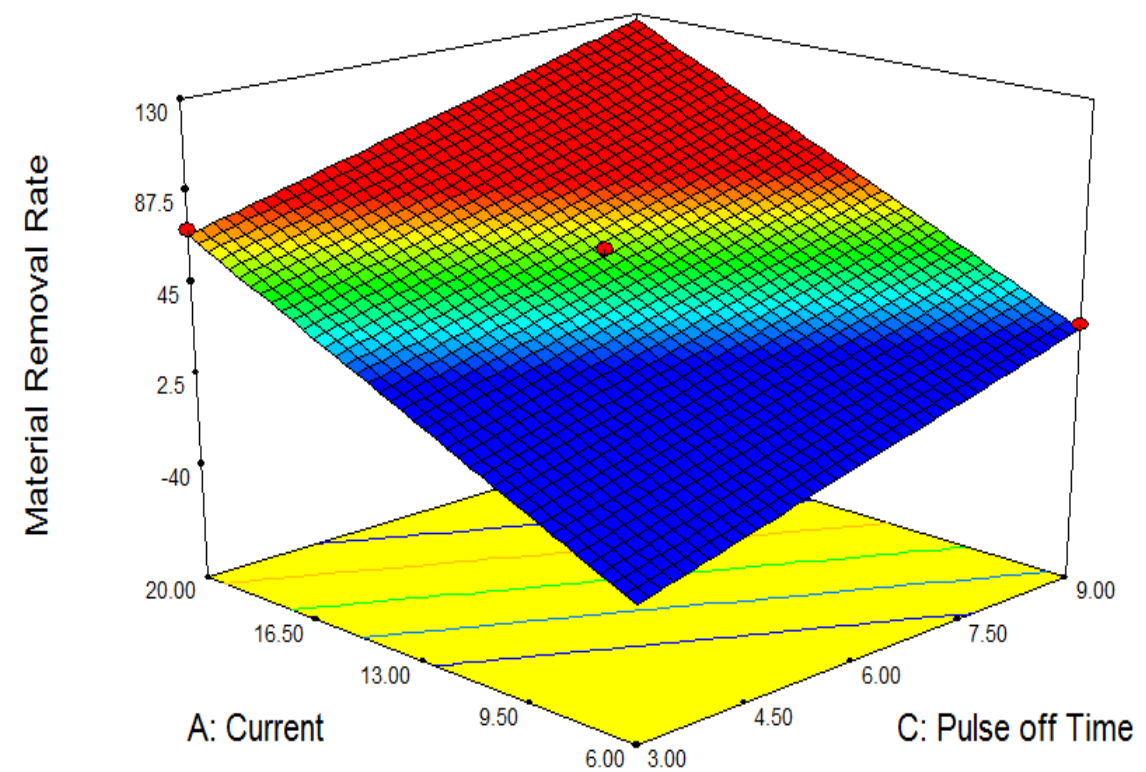

Figure 3 Effect of pulse off time and current over material removal rate.

Figure 2 shows the effect of pulse on time and pulse off time over material removal rate. The Material removal rate remains constant throughout the range of pulse on time whereas the material removal rate has increased linearly with increase in pulse of time. The maximum material removal rate was attained at 80 ampere current and 9.0 seconds of pulse on time.

Figure 3 shows the effect of pulse off time and current over material removal rate. The Material removal rate remains constant throughout the range of pulse on time whereas the material removal rate has increased linearly with both increased in current and pulse off time. The maximum material removal rate was attained at 80 seconds of pulse off time and 20 amperecurrent. 
Table 3 ANOVA for MRR

\begin{tabular}{|c|c|c|c|c|c|c|}
\hline Source & $\begin{array}{c}\text { Sum of } \\
\text { Squares }\end{array}$ & $\mathbf{d f}$ & $\begin{array}{c}\text { Mean } \\
\text { Square }\end{array}$ & F Value & p-value & Prob> F \\
\hline Model & 3024.14 & 3 & 1008.05 & 46.63 & 0.0004 & significant \\
\hline A-Current & 107.64 & 1 & 107.64 & 4.98 & 0.076 & \\
\hline B-Pulse On Time & 41 & 1 & 41 & 1.9 & 0.2269 & \\
\hline C-Pulse off Time & 35.19 & 1 & 35.19 & 1.63 & 0.2581 & \\
\hline Residual & 108.09 & 5 & 21.62 & & & \\
\hline Cor Total & 3132.23 & 8 & & & & \\
\hline
\end{tabular}

Table 3 indicates that, current is the most contributing parameter followed by pulse on time and pulse off time. The "Pred R-Squared" of 0.8761 is in reasonable agreement with the "Adj R-Squared" of 0.9448. Adeq Precision" measures the signal to noise ratio. A ratio greater than 4 is desirable. The ratio of 15.809 indicates an adequate signal. This model can be used to navigate the design space.

\section{CONCLUSION}

The experiments were conducted based on orthogonal taguchi analysis. The following results were drawn

i. When analysis anova current was identified as the most contributing parameters for material removal rate.

ii. A model was developed for predicting the material removal rate and was found to produces results with very minimum deviations.

iii. The interrelationship between material removal rate and the contributing parameters was studied using the response surface methodology.

\section{REFERENCE}

[1] Murray J.W, Sun J, Patil D.V, Wood T.A, Clare A.T,'Physical and electrical characteristics of EDM debris", Journal of Materials Processing Technology, vol.229, (2016), pp.no 54-60.

[2] Bai Shaoa, Kamlakar P. Rajurkara," Modelling of the crater formation in micro-EDM", Procedia CIRP, vol 33, (2015), pp. no376 - 381.

[3]Mohammad Antar, DimitriosChantzis,

SundarMarimuthu, "High Speed EDM and Laser

Drilling of Aerospace Alloys", Procedia CIRP, vol 42 ( 2016 ), pp. no 526 - 531.

[4] Guo Y, Ling Z, “A magnetic suspension spindle system for micro EDM" Procedia CIRP, vol 42, ( 2016 ), pp. no 543 - 546.

[5]K. RadhaKrishnan, A. Godwin Antony, K. Rajaguru, S. Dinesh, "Experimental Investigation on
Machining of Aluminium Metal Matrix using Electrical Discharge Machining', Advances in Natural and Applied Sciences, vol. 7 (2017), pp.no 809-816.

[6] S. Dinesh, K. Rajaguru, V. Vijayan, A. Godwin Antony, "Investigation and Prediction of Material Removal Rate and Surface Roughness in CNC Turning of EN24 Alloy Steel' Mechanics and Mechanical Engineering Vol. 20, No. 4 (2016), pp.no 451-466

[7] N. Annamalai, V. Sivaramakrishnan, B. Suresh kumar, N.Baskar, "Investigation and Modeling of Electrical Discharge Machining Process Parameters for AISI 4340 steel" International Journal of Engineering and Technology (IJET) Vol. 5, No. 6 (2014), pp.no 4161-4770.

[8] Manish Gangil, Pradhan M. K, "Modeling and optimization of electrical discharge machining process using RSM: A review" Materials Today: Proceedings, Vol. 4 (2017) pg. 1752-176.

[9] Dinesh S, Godwin Antony A, K.Rajaguru, V.Vijayan,, B.Suresh Kumar " Experimental Investigation and Optimization of Machining Parameters in CNC Turning Operation of Duplex Stainless Steel", Asian Journal of Research in Social Sciences and Humanities, Vol. 6, No. 10, October 2016, pp. 179-195.

[10] Dinesh S, Godwin Antony A, K.Rajaguru, V.Vijayan," Experimental Investigation and Optimization of Material Removal Rate and Surface Roughness in Centerless grinding of Magnesium Alloy using Grey Relational Analysis", Mechanics and Mechanical Engineering, Vol 21, No 1 (2017), pp.no

17-28.

[11] Godwin Antony A, Aravind S, Dinesh S, Rajaguru K, Vijayan V," Analysis and Optimization of Performance Parameters in Computerized IC Engine Using Diesel Blended with Linseed Oil and Leishmaan's Solution", Mechanics and Mechanical Engineering, Vol 21, No 2 (2017), pp.no 193-205 